\title{
A modified system for classifying the bilateral superior pulmonary veins using three-dimensional computed tomography bronchography and angiography images
}

\author{
Jun Wang ${ }^{1 \#} \wedge$, Haoran Lin ${ }^{1 \#}$, Chengyu Bian ${ }^{1}$, Zhipeng Chen ${ }^{1}$, Jingjing Huang ${ }^{1}$, Yang Xia ${ }^{1}$, Weibing Wu ${ }^{1}$, \\ Quan Zhu ${ }^{1}$, Mei Yuan ${ }^{2}$, Liang Chen ${ }^{1}$ \\ ${ }^{1}$ Department of Thoracic Surgery, Jiangsu Province People's Hospital and the First Affiliated Hospital of Nanjing Medical University, Nanjing, \\ China; ${ }^{2}$ Department of Radiology, Jiangsu Province People's Hospital and the First Affiliated Hospital of Nanjing Medical University, Nanjing, \\ China \\ Contributions: (I) Conception and design: J Wang, L Chen; (II) Administrative support: L Chen; (III) Provision of study materials or patients: H Lin, \\ Z Chen, C Bian, J Huang; (IV) Collection and assembly of data: J Wang, Y Xia, Mei Yuan, W Wu, Q Zhu; (V) Data analysis and interpretation: L \\ Chen, J Wang; (VI) Manuscript writing: All authors; (VII) Final approval of manuscript: All authors. \\ "These authors contributed equally to this work. \\ Correspondence to: Liang Chen. Department of Thoracic Surgery, Jiangsu Province People's Hospital and the First Affiliated Hospital of Nanjing \\ Medical University, Nanjing 210029, China. Email: clbright0909@njmu.edu.cn.
}

Background: Identifying the distribution of pulmonary veins with three-dimensional reconstruction images is of great significance for surgical guidance. Existing models neglect the consistency of the bilateral superior pulmonary veins (SPVs) and lack a simple unified classification pattern. This study aimed to analyze the distributional features of bilateral SPVs, based on a cohort of patients undergoing CT examination.

Methods: The three-dimensional computed tomography bronchography and angiography (3D-CTBA) images of 1,520 cases were retrospectively analyzed. The reconstructed images of the right upper lobes were read in 715 cases, and left upper lobes in 805 cases. Through symmetrical analysis, the circulation of main venous branches and the spatial relationships of confluences with adjacent bronchus were compared.

Results: The SPVs of bilateral upper lobes showed common distributional features and were divided into three main types. The central vein type, the semi-central vein type, and the non-central vein type accounted for $83.35 \%$ [596], 7.84\% [56], 8.11\% [58] of the 715 cases with right scanning, and $25.71 \%$ [207], 62.61\% [504], 10.81\% [87] of the 805 cases with left scanning, respectively. There were $5(0.70 \%)$ cases with rare variations in the right upper lobe and $7(0.87 \%)$ in the left upper lobe. The attribution of intersubsegmental vein in the posterior segment $\left(\mathrm{V}^{2} \mathrm{~b}\right)$ and its position relative to the anterior segmental bronchus $\left(\mathrm{B}^{3}\right)$ was the basis of classification in the right upper lobe, and the attribution of intersubsegmental vein in the apicoposterior segment $\left(\mathrm{V}^{1+2} \mathrm{c}\right)$ and its position relative to $\mathrm{B}^{3}$ was the basis of classification in the left upper lobe. In this classification system, the branching pattern of the intersegmental vein between the apical segment and the anterior segment $\left(\mathrm{V}^{1} \mathrm{~b}\right)$ in the right upper lobe, and the intersegmental vein between the apicoposterior segment and the anterior segment $\left(\mathrm{V}^{1+2} \mathrm{a}\right)$ in the left upper lobe were used for subdivision.

Conclusions: Our modified system had a high degree of consistency in classifying SPVs in bilateral upper lobes, thus providing guidance for preoperative and intraoperative procedures.

Keywords: Superior pulmonary vein (SPVs); three-dimensional computed tomography bronchography and angiography (3D-CTBA); central vein type; semi-central vein type; non-central vein type

$\wedge$ ORCID: 0000-0002-5975-542X.

(C) Journal of Thoracic Disease. All rights reserved. 
Submitted Jun 14, 2021. Accepted for publication Aug 19, 2021.

doi: $10.21037 /$ jtd-21-985

View this article at: https://dx.doi.org/10.21037/jtd-21-985

\section{Introduction}

Segmentectomy is being widely used in the treatment of early lung cancer (1-3). In this surgery, pulmonary arteries or bronchi are often used to identify the regional circulation of the lesion and the excision margin $(4,5)$. With new imaging technologies, such as three-dimensional computed tomography bronchography and angiography (3D-CTBA), the pulmonary veins can be reconstructed with $3 \mathrm{D}$ models to determine the target zone and surgical path $(6,7)$. However, even with 3D-CTBA images, pulmonary segmentectomy still challenges surgeons who are not familiar with the bronchial and vascular distribution of the lungs, especially pulmonary veins. Therefore, simple and practical 3D models may help surgeons to recognize variations in veins and identify the circulation reflux in the main venous branches. In this study, the branching patterns and symmetricity of bilateral superior pulmonary veins (SPVs) were analyzed through three-dimensional reconstruction techniques. A simple system was established to classify the major branches of SPVs, thus facilitating the implementation of pulmonary segmentectomy.

We present the following article in accordance with the STROBE reporting checklist (available at https://dx.doi. org/10.21037/jtd-21-985).

\section{Methods}

\section{Patient preparation}

We retrospectively analyzed the images of 1,520 patients who underwent CT examination from January 2017 to December 2020. The right upper lobes were examined in 715 cases, and the left upper lobes in 805 cases.

Bronchovascular patterns in the upper lobe were analyzed using 3D-CTBA images. The analysis was performed independently by a radiologist and three thoracic surgeons. If there were different opinions, the final decision was made after discussion. This retrospective study was approved by the Ethics Review Committee of Jiangsu Provincial People's Hospital.

The study was conducted in accordance with the Declaration of Helsinki (as revised in 2013). The study was approved by Jiangsu Province People's Hospital (NO.:
2019-SR-450) and informed consent was taken from all the patients.

\section{CT Scan and 3D Reconstruction}

The patient was scanned with Siemens 64-slice dual-source CT (Somatom Definition), Medrad double-syringe power injector and iopromide 370 (Bayer Healthcare Co., Ltd.). The patient was placed in a supine position with $20-22 \mathrm{G}$ intravenous needles in the anterior cubital vein. Firstly, the time-density curves were obtained by bolus injection. On the CT scout image, the scan layer of the mass injection was set at the level of the aortopulmonary window, which showed the pulmonary trunk, ascending aorta, and descending aorta. Twenty milliliters of contrast was injected at a rate of $5 \mathrm{~mL} / \mathrm{s}$, followed by $20 \mathrm{~mL}$ of normal saline at the same rate. Six seconds after the injection of contrast agent, the same layer scan was performed on the aforementioned layer. 20 scans were performed, with an interval of 2 seconds. The scan was terminated when the density in the aorta began to decrease. The data were used to plot time-density curves within the pulmonary artery and ascending aorta. The phase of maximum pulmonary arteriovenous density difference was also recorded. Then the start time of the scan and the dose of contrast agent were set and the contrast was injected at a rate of $5 \mathrm{~mL} / \mathrm{s}$, followed by $20 \mathrm{~mL}$ of normal saline at the same rate. These settings enabled the lesions, the pulmonary arteries and the aorta to be developed, and, more importantly, the CT value in the pulmonary vein was higher than that in the pulmonary artery, and showed a density difference in images. The whole lung field was scanned with a collimator thickness of $0.6 \mathrm{~mm}$, the reconstructed layer of $1 \mathrm{~mm}$, and the interlayer space of $1 \mathrm{~mm}$. The convolution kernel of reconstruction was a relatively low spatial frequency algorithm (e.g., "standard" or "soft-tissue" algorithms B30), which smoothed the image, reduced visible image noise, and improved the contrast resolution to some degree $(8,9)$. During the scan, the patient held his or her breath as instructed. Attention was paid to prevent potential adverse reactions caused by iodine contrast agent. After image acquisition, the volume data in arterial and venous phases were transmitted to a reconstruction software and 


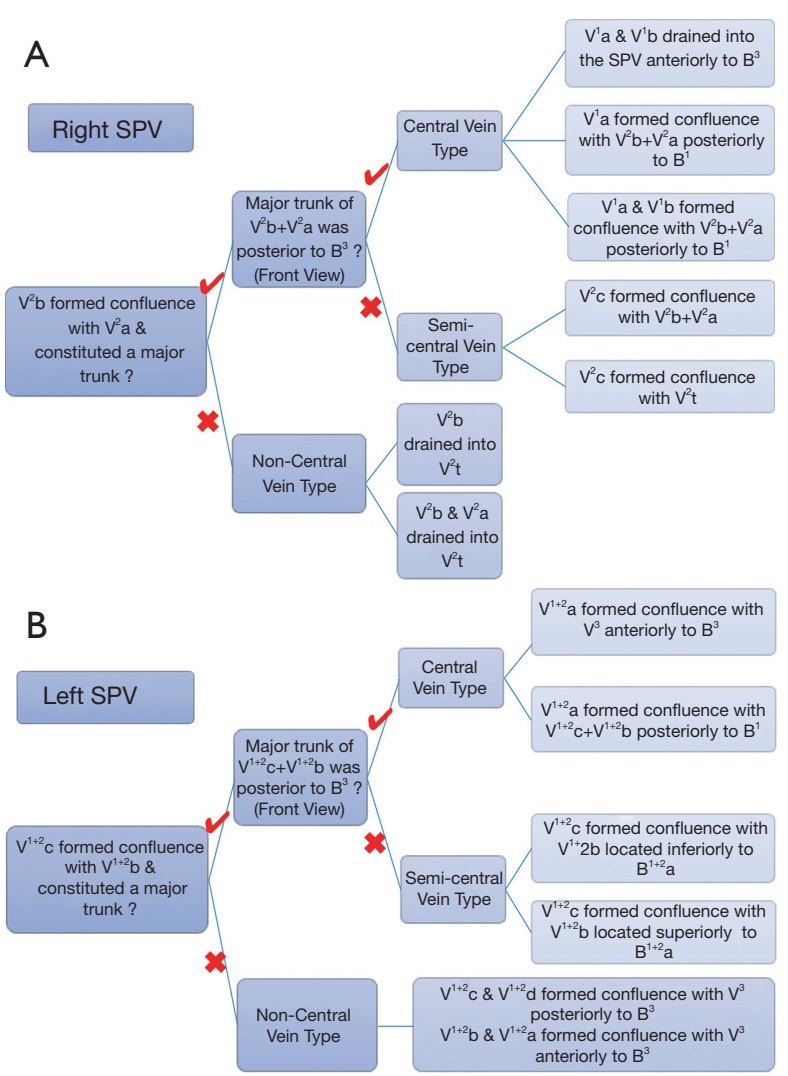

Figure 1 General classification of two-step flow chart. (A) The right SPVs were first classified as central vein type, semi-central vein type or non-central vein type according to whether $\mathrm{V}^{2} \mathrm{~b}$ formed a confluence with $\mathrm{V}^{2} \mathrm{a}$ and constituted a major trunk. If $\mathrm{V}^{2} \mathrm{~b}$ formed a confluence with $\mathrm{V}^{2}$ a and constituted a major trunk, it was classified as the central vein type or the semi-central vein type; otherwise as the non-central vein type. Then, if the $V^{2} b+V^{2}$ a trunk was located posterior to $\mathrm{B}^{3}$, it was classified as the central vein type; otherwise as the semi-central vein type. (B) The left SPVs were first classified as central vein type, semi-central vein type or non-central vein type according to whether $\mathrm{V}^{1+2} \mathrm{c}$ formed a confluence with $\mathrm{V}^{1+2} \mathrm{~b}$ and constituted a major trunk. If $\mathrm{V}^{1+2} \mathrm{c}$ formed a confluence with $\mathrm{V}^{1+2} \mathrm{~b}$ and constituted a major trunk, it was classified as the central vein type or the semi-central vein type; otherwise as the non-central vein type. Then, if the $\mathrm{V}^{1+2} \mathrm{~b}+\mathrm{c}$ trunk was located posterior to $\mathrm{B}^{3}$, it was classified as the central vein type; otherwise as the semi-central vein type. SPV, superior pulmonary veins. converted into $3 \mathrm{D}$-CTBA images. More than $80 \%$ of the reconstructed images showed the fourth branching bronchus, and the undetected blood vessels were thinner than $1 \mathrm{~mm}$ in diameter.

\section{Definition of pulmonary vein type}

The latest international nomenclature was adopted to describe pulmonary veins (10). The methods of Shimizu, Yamashita and Boyden were referred to classify the veins into the central vein type, semi-central vein type and noncentral vein type (11-13). In the right upper lobe, $\mathrm{V}^{1} \mathrm{~b}, \mathrm{~V}^{2} \mathrm{a}$ and $V^{2} c$ were identified as intersegmental veins, while $V^{1} a$, $\mathrm{V}^{2} \mathrm{~b}$ and $\mathrm{V}^{3} \mathrm{a}$ as intersubsegmental veins. To make bilateral SPVs more comparable, we only analyzed the veins in the upper division of the left upper lobes, in which $\mathrm{V}^{1+2} \mathrm{a}, \mathrm{V}^{1+2} \mathrm{~d}$ and $V^{3} b$ were identified as intersegmental veins, while $V^{1+2} b$, $\mathrm{V}^{1+2} \mathrm{c}, \mathrm{V}^{3} \mathrm{a}$ and $\mathrm{V}^{3} \mathrm{c}$ as intersubsegmental veins. The vein distributed between two subsegments of $\mathrm{S}^{1+2}$ a subsegment were labeled as Intra. $\mathrm{V}\left(\mathrm{S}^{1+2}\right.$ a). Vl represented a special vein located centrally in the right upper lobe among the $S^{1}, S^{2}$ and $\mathrm{S}^{3}$ segments, or located centrally in the upper division of the left upper lobe between $\mathrm{S}^{1+2}$ and $\mathrm{S}^{3}$.

In our classification system, "central" was defined as the distribution of the main trunk of the upper pulmonary vein in the center of the lobe. The main trunk of the right upper lobe was $\mathrm{V}^{2}$, while the main trunk of the left upper lobe was $V^{1+2}$. The general SPVs were classified with a two-step method as shown in Figure 1. Specifically, the right SPV was firstly classified as central vein type, semi-central vein type or non-central vein type, according to whether there was a convergence of $\mathrm{V}^{2} \mathrm{~b}$ and $\mathrm{V}^{2} \mathrm{a}$. If $\mathrm{V}^{2} \mathrm{~b}$ converged with $\mathrm{V}^{2} \mathrm{a}$ into a major trunk, it would be the central vein type or the semicentral vein type, otherwise it would be the non-central vein type. Then, if the $\mathrm{V}^{2} \mathrm{~b}+\mathrm{V}^{2}$ a trunk was located posterior to $\mathrm{B}^{3}$, it was classified as the central vein type; otherwise, as the semi-central vein type. According to the same rules, the central vein type, semi-central vein type or non-central vein type in the left upper lobe was determined by whether $\mathrm{V}^{1+2} \mathrm{c}$ and $\mathrm{V}^{1+2} \mathrm{~b}$ converged into a major trunk. If the $\mathrm{V}^{1+2} \mathrm{~b}+\mathrm{c}$ trunk 


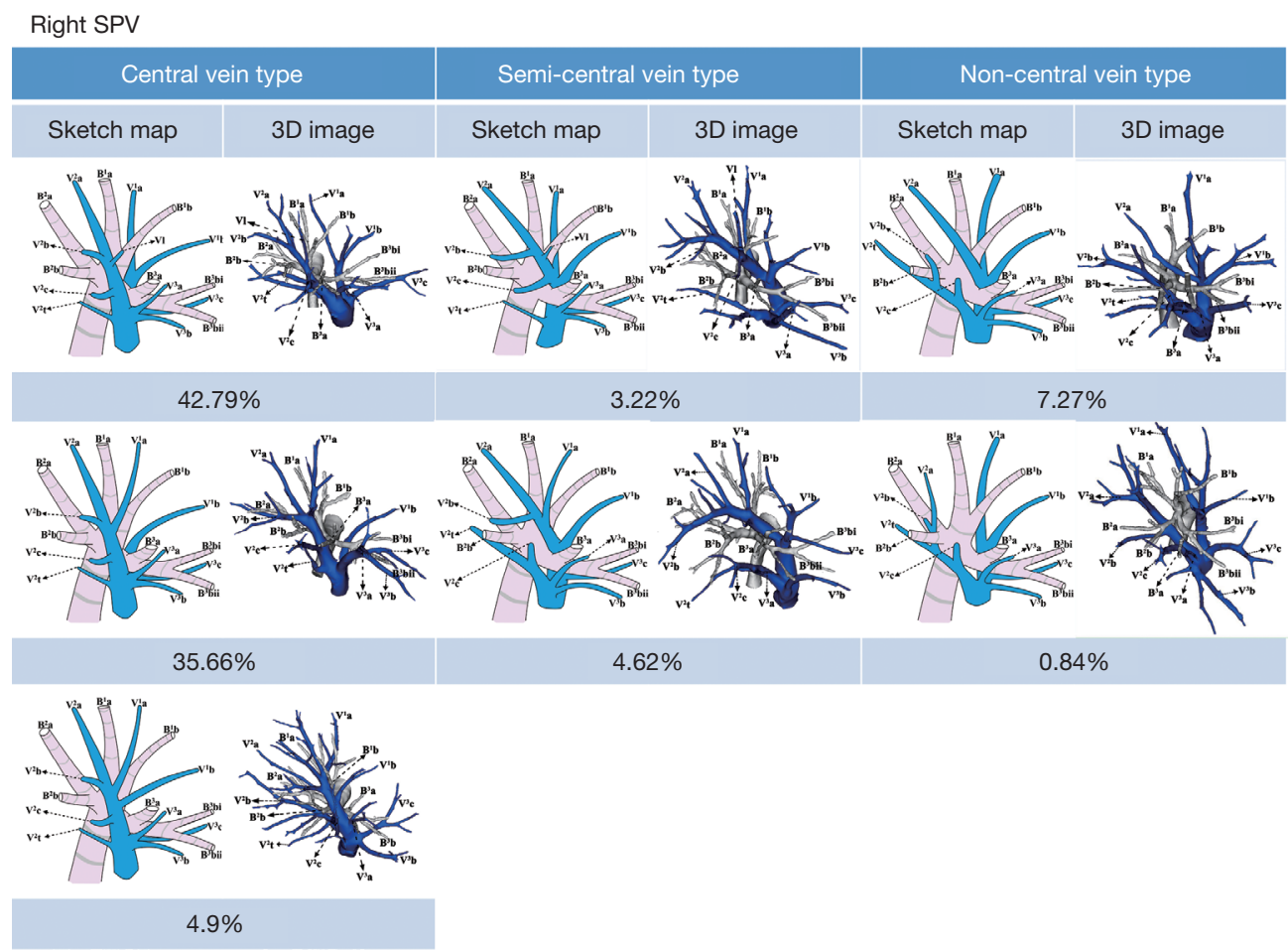

Figure 2 Sketch map and 3D image for general classification of the right SPV. SPV, superior pulmonary veins; 3D, three-dimensional.

was located posterior to $\mathrm{B}^{3}$, it could be defined as the central vein type; otherwise, as semi-central vein type. If there was no convergence of $\mathrm{V}^{1+2} \mathrm{c}$ and $\mathrm{V}^{1+2} \mathrm{~b}$, the branches would be the non-central vein type. Based on this classification method, other major vein branches in bilateral upper lobes were analyzed.

\section{Statistical analysis}

Descriptive statistics were shown as frequency and percentage for categorical variables.

\section{Results}

\section{Distribution of $V^{2} b$ in the right $S P V$}

There were 648 cases (90.63\%) with a single $\mathrm{V}^{2} \mathrm{~b}$ branch in the right upper lobe. The branch formed a confluence with $\mathrm{V}^{2} \mathrm{a}$ in 581 cases $(81.26 \%)$, with $\mathrm{V}^{2} \mathrm{t}$ in 57 cases $(7.97 \%)$, with $\mathrm{V}^{2} \mathrm{c}$ in 4 cases $(0.56 \%)$, and with $\mathrm{V}^{2} \mathrm{~b}$ in 3 cases $(0.42 \%)$ into the inferior pulmonary vein. Direct drainage into the left atrium was found in 3 cases $(0.42 \%)$. There were 67 cases $(9.37 \%)$ with two branches of $\mathrm{V}^{2} \mathrm{~b}$. Respectively, confluences were formed with $\mathrm{V}^{2} \mathrm{a}$ and $\mathrm{V}^{2} \mathrm{t}$ in 51 cases
(7.13\%), with $\mathrm{V}^{2}$ a in 8 cases (1.12\%), with $\mathrm{V}^{2}$ a and $\mathrm{V}^{2} \mathrm{c}$ in 7 cases $(0.98 \%)$; besides, in 1 case $(0.14 \%)$, one branch formed a confluence with $\mathrm{V}^{2} \mathrm{a}$ and the other branch drained into the inferior pulmonary vein.

\section{Distribution of the right SPVs in the central vein type}

In 596 cases $(83.35 \%), \mathrm{V}^{2} \mathrm{~b}$ converged with $\mathrm{V}^{2}$ a into a major trunk posterior to $\mathrm{B}^{3}$, running through the center of the right upper lobe, and probably receiving drainage from $V^{1} a, V^{1} b, V^{2} c$, and Vl. SPVs in this distribution were defined as the central vein type. Of these cases, 306 cases $(42.79 \%)$ were assigned to the first subtype in which $\mathrm{V}^{2}$ was dissociated with $\mathrm{V}^{1}$ and $\mathrm{V}^{3}$, and passed between $\mathrm{B}^{2}$ and $\mathrm{B}^{3} ; 255$ cases $(35.66 \%)$ to the second subtype in which $\mathrm{V}^{1} \mathrm{a}$ formed a confluence with the $\mathrm{V}^{2} \mathrm{~b}+\mathrm{V}^{2}$ a trunk posterior to $\mathrm{B}^{1} ; 35$ cases $(4.90 \%)$ to the third subtype in which $\mathrm{V}^{1} \mathrm{a}$ and $\mathrm{V}^{1} \mathrm{~b}$ formed a confluence with the $\mathrm{V}^{2} \mathrm{~b}+\mathrm{V}^{2} \mathrm{a}$ trunk posterior to $\mathrm{B}^{1}$ (Figure 2).

In the central vein type, $\mathrm{V}^{2} \mathrm{c}$ formed a confluence with the $\mathrm{V}^{2} \mathrm{~b}+\mathrm{V}^{2} \mathrm{a}$ trunk in 590 cases $(82.52 \%)$, with $\mathrm{V}^{2} \mathrm{~b}$ in 2 cases $(0.28 \%)$, with $V^{2} t$ in 3 cases $(0.42 \%)$, and with $V^{3}$ in 1 case $(0.14 \%)$. Vl vein was observed in 456 cases $(63.78 \%)$. 


\section{Distribution of the right SPVs in the semi-central vein type}

In 56 cases $(7.84 \%), \mathrm{V}^{2} \mathrm{~b}$ converged with $\mathrm{V}^{2}$ a into the $\mathrm{V}^{2} \mathrm{~b}+\mathrm{V}^{2}$ a trunk located anterior to $\mathrm{B}^{3}$, running through the center of the right upper lobe, and probably receiving drainage from $V^{1} a, V^{1} b, V^{2} c$, and Vl. SPVs in this distribution were defined as the semi-central vein type. Of these cases, 23 cases $(3.22 \%)$ were assigned to the first subtype in which $V^{1}$ a formed a confluence with the $V^{2} b+V^{2} a$ trunk anterior to $\mathrm{B}^{1} ; 33$ cases $(4.62 \%)$ to the second subtype in which $\mathrm{V}^{1}$ a formed a confluence with the $\mathrm{V}^{2} \mathrm{~b}+\mathrm{V}^{2} \mathrm{a}$ trunk posterior to $\mathrm{B}^{1}$ (Figure 2).

In the semi-central vein type, $\mathrm{V}^{2} \mathrm{c}$ formed a confluence with $\mathrm{V}^{2} \mathrm{~b}+\mathrm{V}^{2}$ a trunk in 29 cases $(4.06 \%)$, with $\mathrm{V}^{2} \mathrm{~b}$ in 2 cases $(0.28 \%)$, with $\mathrm{V}^{2} \mathrm{t}$ in 17 cases $(2.38 \%)$, with $\mathrm{V}^{3}$ in 7 cases $(0.98 \%)$, and drained directly into the SPV in 1 case $(0.14 \%)$. Vl vein was observed in 25 cases $(3.50 \%)$.

\section{Distribution of the right SPVs in the non-central vein type}

In 58 cases $(8.11 \%), \mathrm{V}^{2} \mathrm{~b}$ and $\mathrm{V}^{2} \mathrm{a}$ did not form a confluence in the center of the right upper lobe. SPVs in this distribution were defined as the non-central vein type. In these cases, 52 cases $(7.27 \%)$ were assigned to the first subtype in which $\mathrm{V}^{2}$ a formed a confluence with $\mathrm{V}^{1}$, and $\mathrm{V}^{2} \mathrm{~b}$ with $\mathrm{V}^{2} \mathrm{t} ; 6$ cases $(0.84 \%)$ to the second subtype in which $V^{2} b$ and $V^{2} a$ formed a confluence with $V^{2} t$ or separately drained into $\mathrm{V}^{2}$ posterior to $\mathrm{B}^{2}$ (Figure 2).

In the non-central vein type, $\mathrm{V}^{2} \mathrm{c}$ formed a confluence with $\mathrm{V}^{2} \mathrm{t}$ in 46 cases $(6.43 \%)$, with $\mathrm{V}^{2} \mathrm{~b}$ in 6 cases $(0.84 \%)$, with $\mathrm{V}^{3}$ in 3 cases $(0.42 \%)$, with $\mathrm{V}^{2}$ a in 2 cases $(0.28 \%)$, and with $\mathrm{V}^{1} \mathrm{a}+\mathrm{V}^{1} \mathrm{~b}$ in 1 case $(0.14 \%)$. $\mathrm{Vl}$ vein was observed in 2 cases $(0.28 \%)$.

\section{Rare variations in the right SPVs}

Five cases $(0.70 \%)$ with independent $\mathrm{V}^{2}$ draining into the inferior pulmonary vein behind the hilum were specified as rare variations, and these cases were excluded from the above classification system.

\section{Distribution of $V^{1+2} c$ in the left SPVs}

There were 775 cases $\left(96.27 \%\right.$ ) with a single $\mathrm{V}^{1+2} \mathrm{c}$ branch in the left upper lobe. The branch formed a confluence with $\mathrm{V}^{1+2} \mathrm{~b}$ in 612 cases $(76.02 \%)$, with $\mathrm{V}^{1+2} \mathrm{a}+\mathrm{b}$ in 79 cases (9.81\%), with $\mathrm{V}^{3}$ in 84 cases $(10.44 \%)$. There were 30 cases
(3.73\%) with two branches of $\mathrm{V}^{1+2} \mathrm{c}$ in the left upper lobe. In 10 cases $(1.24 \%)$, one branch converged with $\mathrm{V}^{1+2} \mathrm{~b}$ into $\mathrm{V}^{1+2} \mathrm{a}$ anterior to $\mathrm{B}^{1+2} \mathrm{a}+\mathrm{b}$, and the other into $\mathrm{V}^{1+2}$ a posterior to $\mathrm{B}^{1+2} \mathrm{a}+\mathrm{b}$. In 11 cases $(1.37 \%)$, one branch converged with $\mathrm{V}^{1+2} \mathrm{~b}$ anterior to $\mathrm{B}^{1+2} \mathrm{a}+\mathrm{b}$, and the other with $\mathrm{V}^{1+2} \mathrm{a}$ posterior to $\mathrm{B}^{1+2} \mathrm{a}+\mathrm{b}$. In 5 cases $(0.62 \%)$, one branch converged with $\mathrm{V}^{1+2} \mathrm{a}+\mathrm{b}$ anterior to $\mathrm{B}^{1+2} \mathrm{a}+\mathrm{b}$, and the other with $\mathrm{V}^{1+2} \mathrm{a}+\mathrm{b}$ posterior to $\mathrm{B}^{1+2} \mathrm{a}+\mathrm{b}$. In 3 cases $(0.37 \%)$, one branch converged with $\mathrm{V}^{3}$ inferior to $\mathrm{B}^{3}$, and the other with $\mathrm{V}^{1+2} \mathrm{a}+\mathrm{b}$ posterior to $\mathrm{B}^{1+2} \mathrm{a}+\mathrm{b}$. In 1 case $(0.12 \%)$, one branch converged with $\mathrm{V}^{1+2} \mathrm{~b}$ anterior to $\mathrm{B}^{1+2} \mathrm{a}+\mathrm{b}$, and the other branch drained into the inferior pulmonary vein behind the hilum.

In the left upper lobe, a single $\mathrm{V}^{1+2} \mathrm{~b}$ branch was observed in 688 cases $\left(85.47 \%\right.$ ); two $\mathrm{V}^{1+2} \mathrm{~b}$ branches were observed in 117 cases (14.53\%), including 10 cases (1.24\%) with two $\mathrm{V}^{1+2} \mathrm{~b}+\mathrm{c}$ branches converged with $\mathrm{V}^{1+2}$ a anterior and posterior to $\mathrm{B}^{1+2} \mathrm{a}+\mathrm{b}, 107$ cases (13.29\%) with two $\mathrm{V}^{1+2} \mathrm{~b}$ branches converged with $\mathrm{V}^{1+2} \mathrm{a}$ anterior and posterior to $\mathrm{B}^{1+2} \mathrm{a}+\mathrm{b}$, respectively.

\section{Distribution of the left SPVs in the central vein type}

In 207 cases $(25.71 \%), \mathrm{V}^{1+2} \mathrm{c}$ converged with $\mathrm{V}^{1+2} \mathrm{~b}$ into the $\mathrm{V}^{1+2} \mathrm{~b}+\mathrm{V}^{1+2} \mathrm{c}$ trunk located posterior to $\mathrm{B}^{3}$, running through the center of the left upper lobe, and probably receiving the drainage of $\mathrm{V}^{1+2} \mathrm{a}$, intrasegmental vein of $\mathrm{S}^{1+2} \mathrm{a}, \mathrm{Vl}$ and $\mathrm{V}^{1+2} \mathrm{~d}$. SPVs in this distribution were defined as the central vein type. Of them, 175 cases $(21.74 \%)$ were assigned to the first subtype in which the confluence of $\mathrm{V}^{1+2} \mathrm{~b}+\mathrm{V}^{1+2} \mathrm{c}$ was independent of the confluence of $\mathrm{V}^{1+2} \mathrm{a}+\mathrm{V}^{3} \mathrm{c}$, and passed between $\mathrm{B}^{3}$ and $\mathrm{B}^{4+5}$ in the center of the left upper lobe; 32 cases $(3.97 \%)$ to the second subtype in which $\mathrm{V}^{1+2}$ a converged with the $\mathrm{V}^{1+2} \mathrm{~b}+\mathrm{V}^{1+2} \mathrm{c}$ trunk posterior to $\mathrm{B}^{3}$ (Figure 3).

In the central vein type, all cases showed the confluence of $\mathrm{V}^{1+2} \mathrm{~d}$ with the $\mathrm{V}^{1+2} \mathrm{~b}+\mathrm{V}^{1+2} \mathrm{c}$ trunk. $\mathrm{Vl}$ vein was observed in 152 cases (18.88\%).

\section{Distribution of the left SPVs in the semi-central vein type}

In 504 cases $(62.61 \%), \mathrm{V}^{1+2} \mathrm{c}$ converged with $\mathrm{V}^{1+2} \mathrm{~b}$ into the $\mathrm{V}^{1+2} \mathrm{~b}+\mathrm{V}^{1+2} \mathrm{c}$ trunk located anterior to $\mathrm{B}^{3}$, running through the center of the left upper lobe, and probably receiving the drainage of $\mathrm{V}^{1+2} \mathrm{a}$, intrasegmental vein of $\mathrm{S}^{1+2} \mathrm{a}, \mathrm{Vl}$ and $\mathrm{V}^{1+2} \mathrm{~d}$. SPVs in this distribution were defined as the semi-central vein type. Of them, 418 cases $(51.93 \%)$ were assigned to the first subtype in which $\mathrm{V}^{1+2} \mathrm{~b}$ was located inferior to $\mathrm{B}^{1+2} \mathrm{a}$ 


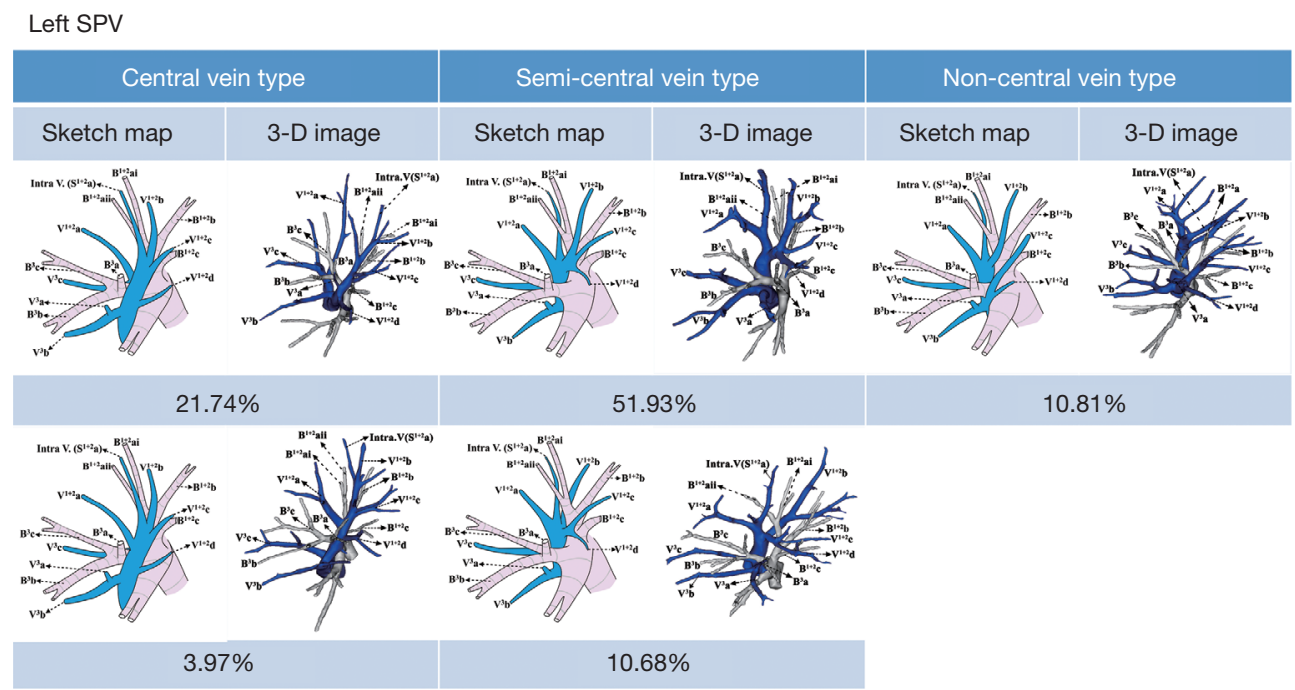

Figure 3 Sketch map and 3D image for general classification of the left SPV. SPV, superior pulmonary veins; 3D, three-dimensional.

and received the drainage of $\mathrm{V}^{1+2} \mathrm{c} ; 86$ cases $(10.68 \%)$ to the second subtype in which $\mathrm{V}^{1+2} \mathrm{~b}$ was located superior to $\mathrm{B}^{1+2} \mathrm{a}$ and received the drainage of $\mathrm{V}^{1+2} \mathrm{c}$ (Figure 3).

In the semi-central vein type, 440 cases (54.66\%) showed a single $\mathrm{V}^{1+2} \mathrm{~d}$ branch in the left upper lobe, including 300 cases $(37.27 \%)$ with a confluence with $\mathrm{V}^{3}, 140$ cases $(17.39 \%)$ with $\mathrm{V}^{1+2}$. The left 64 cases $(7.95 \%)$ showed two branches of $\mathrm{V}^{1+2} \mathrm{~d}$ in the left upper lobe, with confluences formed with $\mathrm{V}^{3}$ and $\mathrm{V}^{1+2}$, respectively. $\mathrm{Vl}$ vein was observed in 414 cases $(51.43 \%)$.

\section{Distribution of the left SPVs in the non-central vein type}

In 87 cases $(10.81 \%), \mathrm{V}^{1+2} \mathrm{c}$ and $\mathrm{V}^{1+2} \mathrm{~b}$ did not converge in the center of the left upper lobe. $\mathrm{V}^{1+2} \mathrm{c}$ and $\mathrm{V}^{1+2} \mathrm{~d}$ formed a confluence with $\mathrm{V}^{3}$ posterior to $\mathrm{B}^{3}$, while $\mathrm{V}^{1+2} \mathrm{~b}$ and $\mathrm{V}^{1+2} \mathrm{a}$ formed a confluence with $\mathrm{V}^{3}$ anterior to $\mathrm{B}^{3}$ (Figure 3). SPVs in this distribution were defined as the non-central vein type. Vl vein was observed in 25 cases $(3.11 \%)$.

\section{Rare variations in the left SPVs}

Seven cases $(0.87 \%)$ with rare variations were excluded from our classification system, including 4 cases $(0.50 \%)$ for a three segmental bronchus pattern symmetrical to the right upper lobe, 1 case $(0.12 \%)$ for transposition deformity of the great arteries, 1 case $(0.12 \%)$ for persistent left superior vena cava and $\mathrm{V}^{1+2} \mathrm{~b}+\mathrm{V}^{1+2} \mathrm{c}$ posterior to $\mathrm{B}^{1+2} \mathrm{~b}+\mathrm{B}^{1+2} \mathrm{c}$ (with similar location of $\mathrm{V}^{2} \mathrm{t}$ in the right upper lobe), and another
1 case $(0.12 \%)$ for $\mathrm{V}^{1+2} \mathrm{~b}+\mathrm{V}^{1+2} \mathrm{c}$ converged with $\mathrm{V}^{3}$ between $\mathrm{A}^{1+2}$ and $\mathrm{B}^{1+2}$.

\section{Discussion}

Continuous refreshment has been seen in the anatomical knowledge about the pulmonary veins (11-15). In 1936, Herrnheiser and Kurat (16) described the relative positions of SPV branches in the chest cavity and classified them as the subpleuro-mediastinal veins, the pectoral veins, and the combined apical and axillary veins, but the spatial relationships of these veins with the arteries and bronchus were not characterized. In 1944, Appleton (17) first claimed that all the veins, either superficial or deep, run across intersegmental demarcation, and proposed the method of defining the intersegmental planes and veins in pulmonary segmental resection. However, all these studies have not compared the distributional features of the veins in bilateral upper lobes. In traditional anatomy, leaving aside the influence of horizontal fissure, the right upper lobe corresponds to the upper division of the left upper lobe, while the right middle lobe corresponds to the lingula segment of the left upper lobe (18). When taking the pulmonary lobe as one surgical unit, the bilateral SPVs are involved. Therefore, the venous patterns of the bilateral upper lobes are often analyzed independently in both traditional anatomy and surgery.

In 1945, Boyden adopted Jackson and Huber's method (19) to name the bronchi, and corresponding arteries and veins 
with numbers (20). This method deepens the research on pulmonary veins. In 1954, Boyden summarized the distributional features of the veins according their relative positions to adjacent bronchi, pointing out that the left SPVs were mainly distributed at shallower depths, which was different from those right SPVs (13). Yamashita was the first finding similarities between the venous distribution patterns in bilateral upper lobes (12). He also pioneered new ideas of using imaging tools to study anatomy. At present, $3 \mathrm{D}$ reconstruction technology is being replicated in the implementation of clinical surgeries (21-23). According to the location of the vein trunk, Yamashita first divided the right SPV into the central vein type $\left(V^{1}, V^{2+3}\right.$ type), the semicentral vein type $\left(\mathrm{V}^{1+2}, \mathrm{~V}^{3}\right.$ type), and the non-central vein type $\left(V^{1+(2 a)}, V^{2} t\right.$ type). Excluding the lingula segment, he further symmetrized the $\mathrm{S}^{1+2} \mathrm{a}, \mathrm{S}^{1+2} \mathrm{~b}, \mathrm{~S}^{1+2} \mathrm{c}$ and $\mathrm{S}^{3}$ in the left upper lobe to the $S^{1}, S^{2} a, S^{2} b$ and $S^{3}$ in the right upper lobe, and named the venous branches in both lobes with consistent digital marks. He found that $\mathrm{V}^{1+2}$ type accounted for the highest proportion in the left upper lobe (70\%), so did the semi-central vein type in the right upper lobe. So, he listed the semi-central vein type of the right upper pulmonary veins as the left upper lobe type, and only defined the $\mathrm{V}^{3+2}$ as the central vein type, neglecting the semi-central vein type or non-central vein type in the left upper lobe.

In our study, according to the reflux attribution of main venous branches and their positions relative to the adjacent bronchi, a new method was adopted for naming the SPVs in bilateral upper lobes. Our analysis showed that the SPVs in both lobes could be divided into the central vein type, the semi-central vein type and the non-central vein type, making up $83.35 \%, 7.84 \%, 8.11 \%$ in the right and $25.71 \%$, $62.61 \%, 10.81 \%$ in the left, respectively. In Yamashita's results, these proportions were $78.3 \%$ (central vein type), $10.6 \%$ (semi-central vein type) and $11.1 \%$ (non-central vein type) in the right, and $17.5 \%$ (central vein type), $70 \%\left(\mathrm{~V}^{1+2}\right.$ type) and $12.5 \%\left(\mathrm{~V}^{1+2} \mathrm{a}, \mathrm{V}^{3+2}\right.$ bc type) in the left. In general, the proportions of each type were close in both classification systems. Our study modified Yamashita's system and included some rare cases. It showed that the central vein type was the most common in the right upper lobe, while the semi-central vein type was the most common in the left upper lobe, indicating that the right upper pulmonary veins were mostly distributed in the central part of the lobe, while the left upper pulmonary veins were mostly distributed in the anterosuperior area.

According to the distribution of main branches $\mathrm{V}^{1}$ and $\mathrm{V}^{2}$, Shimizu (11) divided the right SPVs into the anterior with central Iab type $\left(V^{1} a+V^{1} b\right.$ located anterior to $B^{3}$, and $V^{2} a+V^{2} b+V^{2} c$ located posterior to $B^{3}, 54 \%$ ), anterior with central $\mathrm{Ib}$ type (only $\mathrm{V}^{1} \mathrm{~b}$ located anterior to $\mathrm{B}^{3}$, and $V^{1} a+V^{2} a+V^{2} b+V^{2} c$ located posterior to $\left.B^{3}, 26 \%\right)$, central type $\left(V^{1} a+V^{1} b+V^{2} a+V^{2} b+V^{2} c\right.$ all located posterior to $B^{3}$, $7 \%)$ and anterior type $\left(V^{1} a+V^{1} b+V X^{2} a\right.$ located anterior to $\mathrm{B}^{3}, \mathrm{~V}^{2} \mathrm{~b}+\mathrm{V}^{2} \mathrm{c}$ located posterior to $\left.\mathrm{B}^{3}, 12 \%\right)$. In this system based on $3 \mathrm{D}$ reconstruction images, only those with all $\mathrm{V}^{1}$ and $\mathrm{V}^{2}$ branches located posterior to $\mathrm{B}^{3}$ were defined as the central type, accounting for 7\%. In the systems of Boyden and Yamashita, this type was not listed. In the collapsed lungs, the spatial relationships between blood vessels and bronchi change with contraction and deformation. On the 3D images of physiological inflated lungs, we found $4.90 \%$ of $\mathrm{V}^{1} \mathrm{a}$ and $\mathrm{V}^{1} \mathrm{~b}$ formed confluences with the $\mathrm{V}^{2} \mathrm{~b}+\mathrm{V}^{2} \mathrm{a}$ trunk posterior to $\mathrm{B}^{1}$, and classified it as the third subtype of the central vein type. Compared with Shimizu's study, our classification system focused on the $\mathrm{V}^{2}$ vein receiving drainage of lots of intersegmental veins, such as $V^{2} a, V^{2} c$ and Vl, and playing an important role in the right SPV. In addition, Shimizu's classification system for the right SPVs cannot be applied to the left SPV. However, both Shimizu's and our systems indicate that some cases lack superficial veins in the anterosuperior area of the right upper lobe. It is necessary to match the intraoperative anatomical structures with 3D CTBA images to avoid misjudgment.

Nowadays, the lung operation can be performed on segmental and even subsegmental levels. In preoperative simulation with 3D CTBA images, pulmonary veins are critical landmarks in determining target segments and surgical paths. We have found certain commonalities in the distributional features of the pulmonary vein trunk and its branches. According to the two-step method (Figure 1), the veins in bilateral upper lobes can be classified into the central vein type, the semi-central vein type and the noncentral vein type. It should be noted that this study only summarized the general distributional features, which may also show individual differences. For example, $V^{2} b$ may have two branches, forming confluences with $\mathrm{V}^{2}$ a superior to $\mathrm{B}^{2}$ and with $\mathrm{V}^{2} \mathrm{t}$ inferior to $\mathrm{B}^{2}$ respectively. It is also possible for $V^{2} b$ to form a confluence with $V^{2} t$ or $V^{2} c$. But the fundamental basis for general classification is the confluence of different branches and location of the confluent trunk. In the present study, the second subtype of the non-central vein type is a typical example. Though $\mathrm{V}^{2} \mathrm{~b}$ and $\mathrm{V}^{2}$ a formed a confluence into $\mathrm{V}^{2} \mathrm{t}$, there was no trunk in the center of the lobe. It is worth noting that a statistically higher proportion of lateral veins has been found in bilateral upper 
lobes. In Yamashita's work, this branch was marked by $\mathrm{V}^{1} 1$ (a lateral branch of $\mathrm{V}^{1}$ ). This vein runs among $\mathrm{S}^{1}, \mathrm{~S}^{2}$ and $\mathrm{S}^{3}$ in the right upper lobe, and usually drains into $\mathrm{V}^{2} \mathrm{a}+\mathrm{V}^{2} \mathrm{~b}$ or $\mathrm{V}^{1}$. There is also a similar vein running between $\mathrm{S}^{1+2}$ and $\mathrm{S}^{3}$ in the left upper lobe and usually draining into $\mathrm{V}^{1+2}$. This lateral vein usually appears in the central vein type and the semi-central vein type. Emitted between several intersegmental veins and located among several adjacent subsegments, it was named as $\mathrm{Vl}$ on both sides in our system. In anatomical sublobar resection for deep lesions adjacent to $\mathrm{Vl}$, the target area should involve more segments or subsegments and the surgical difficulty would increase accordingly.

This study still has some limitations. First, due to the morphological difference between the bilateral upper lobes, we only compared the right upper lobe with the upper division of the left upper lobe, thus lacking a comparative analysis of other symmetric regions. When we compared the lingual vein with the right middle lobe pulmonary vein, or compared bilateral inferior pulmonary veins, no general distributional features were found based on the location of the venous trunk, but the confluent venous branches and corresponding proportions are worth further analysis. Second, we only summarized the general distributional features of veins in bilateral upper lobes, and should explore the spatial relationships of veins with arteries and bronchus. In addition, despite strict selection of high quality $3 \mathrm{D}$ CTBA images, subtle differences between imaged SPVs and intraoperatively observed SPVs are inevitable.

\section{Conclusions}

The distributional features of bilateral SPVs were analyzed with 3D CTBA images for the first time. Our modified system is simpler and highly consistent in classifying bilateral upper lobes, and is expected to be widely used for preoperative planning and intraoperative guidance.

\section{Acknowledgments}

We would like to thank Mr. Yongke Cao for his help in polishing our paper.

Funding: This work was supported in part by key medical research project of Jiangsu Provincial Health Commission (K2019002), Ethicon Excellence in Surgery Grant (HZB20190528-13), and Jiangsu Province Natural Science Foundation (BK20201492).

\section{Footnote}

Reporting Checklist: The authors have completed the STROBE reporting checklist. Available at https://dx.doi. org/10.21037/jtd-21-985

Data Sharing Statement: Available at https://dx.doi. org/10.21037/jtd-21-985

Peer Review File: Available at https://dx.doi.org/10.21037/ jtd-21-985

Conflicts of Interest: All authors have completed the ICMJE uniform disclosure form (available at https://dx.doi. org/10.21037/jtd-21-985). All authors report funding supports (partly) from key medical research project of Jiangsu Provincial Health Commission (K2019002), Ethicon Excellence in Surgery Grant (HZB-2019052813), and Jiangsu Province Natural Science Foundation (BK20201492).

Etbical Statement: The authors are accountable for all aspects of the work in ensuring that questions related to the accuracy or integrity of any part of the work are appropriately investigated and resolved. The study was conducted in accordance with the Declaration of Helsinki (as revised in 2013). The study was approved by Jiangsu Province People's Hospital (NO.: 2019-SR-450) and informed consent was taken from all the patients.

Open Access Statement: This is an Open Access article distributed in accordance with the Creative Commons Attribution-NonCommercial-NoDerivs 4.0 International License (CC BY-NC-ND 4.0), which permits the noncommercial replication and distribution of the article with the strict proviso that no changes or edits are made and the original work is properly cited (including links to both the formal publication through the relevant DOI and the license). See: https://creativecommons.org/licenses/by-nc-nd/4.0/.

\section{References}

1. Ghaly G, Kamel M, Nasar A, et al. Video-Assisted Thoracoscopic Surgery Is a Safe and Effective Alternative to Thoracotomy for Anatomical Segmentectomy in Patients With Clinical Stage I Non-Small Cell Lung Cancer. Ann Thorac Surg 2016;101:465-72; discussion 472. 
2. Suzuki K, Saji H, Aokage K, et al. Comparison of pulmonary segmentectomy and lobectomy: Safety results of a randomized trial. J Thorac Cardiovasc Surg 2019;158:895-907.

3. Stamatis G, Leschber G, Schwarz B, et al. Perioperative course and quality of life in a prospective randomized multicenter phase III trial, comparing standard lobectomy versus anatomical segmentectomy in patients with nonsmall cell lung cancer up to $2 \mathrm{~cm}$, stage IA (7th edition of TNM staging system). Lung Cancer 2019;138:19-26.

4. Chan EG, Landreneau JR, Schuchert MJ, et al. Preoperative (3Dimensional) computed tomography lung reconstruction before anatomic segmentectomy or lobectomy for stage I non-small cell lung cancer. J Thorac Cardiovasc Surg 2015;150:523-8.

5. Hu W, Zhang $\mathrm{K}$, Han X, et al. Three-dimensional computed tomography angiography and bronchography combined with three-dimensional printing for thoracoscopic pulmonary segmentectomy in stage IA nonsmall cell lung cancer. J Thorac Dis 2021;13:1187-95.

6. Oizumi H, Endoh M, Takeda S, et al. Anatomical lung segmentectomy simulated by computed tomographic angiography. Ann Thorac Surg 2010;90:1382-3.

7. Wu WB, Xu XF, Wen W, et al. Thoracoscopic Pulmonary Sub-Subsegmentectomy Based on Three-Dimensional Images. Ann Thorac Surg 2016;102:e389-91.

8. Mayo JR. High resolution computed tomography. Technical aspects. Radiol Clin North Am 1991;29:1043-9.

9. Mayo JR. The high-resolution computed tomography technique. Semin Roentgenol 1991;26:104-9.

10. Standring S. Gray's Anatomy. 40th Edition. Elsevier, 2008.

11. Shimizu K, Nagashima T, Ohtaki Y, et al. Analysis of the variation pattern in right upper pulmonary veins and establishment of simplified vein models for anatomical segmentectomy. Gen Thorac Cardiovasc Surg 2016;64:604-11.

Cite this article as: Wang J, Lin $\mathrm{H}$, Bian C, Chen Z, Huang J, Xia Y, Wu W, Zhu Q, Yuan M, Chen L. A modified system for classifying the bilateral superior pulmonary veins using three-dimensional computed tomography bronchography and angiography images. J Thorac Dis 2021;13(10):5933-5941. doi: $10.21037 / j t d-21-985$
12. Yamashita H. Roentgenologic Anatomy of the Lung. New York: Igaku-Shoin Medical Publishers, 1978.

13. Boyden EA. Segmental Anatomy of The Lung. New York: McGraw Hill, 1954.

14. Zhang M, Mao N, Zhang K, et al. Analysis of the variation pattern in left upper division veins and establishment of simplified vein models for anatomical segmentectomy. Ann Transl Med 2020;8:1515.

15. Maki R, Miyajima M, Ogura K, et al. Pulmonary vessels and bronchial anatomy of the left lower lobe. Surg Today 2020;50:1081-90.

16. Herrnheiser G, Kubat A. Systematische Anatomie der Lungengefässe. Zeitschrift für Anatomie und Entwicklungsgeschichte 1936;105:570-653.

17. Appleton AB. Segments and blood-vessels of the lungs. Lancet 1944;244:592-4.

18. Nelson HP. Postural drainage of the lungs. Br Med J 1934;2:251-5.

19. Jackson CL, Huber JF. Correlated applied anatomy of the bronchial tree and lungs with a system of nomenclature. Dis Chest 1943;9:319-26.

20. Boyden EA. The intrahilar and related segmental anatomy of the lung. Surgery 1945;18:706-31.

21. Stortecky S, Heg D, Gloekler S, et al. Accuracy and reproducibility of aortic annulus sizing using a dedicated three-dimensional computed tomography reconstruction tool in patients evaluated for transcatheter aortic valve replacement. EuroIntervention 2014;10:339-46.

22. Ni ZK, Lin D, Wang ZQ, et al. Precision Liver Resection: Three-Dimensional Reconstruction Combined with Fluorescence Laparoscopic Imaging. Surg Innov 2021;28:71-8.

23. Wu WB, Xia Y, Pan XL, et al. Three-dimensional navigation-guided thoracoscopic combined subsegmentectomy for intersegmental pulmonary nodules. Thorac Cancer 2019;10:41-6. 